\title{
Subchondral Bone and Its Role in Osteoarthritis
}

\author{
Esat Uygur1, Bulent Kilic ${ }^{2}$, Murat Demiroglu ${ }^{3 *}$, Korhan Ozkan ${ }^{3}$, Hakan Turan Cift ${ }^{4}$ \\ ${ }^{1}$ Vera Hospital, Orthopedics and Traumatology, Istanbul, Turkey \\ ${ }^{2}$ Gelisim University Health Sciences, Istanbul, Turkey \\ ${ }^{3}$ Department of Orthopaedics and Traumatology, Medeniyet University Goztepe Training and Research \\ Hospital, Istanbul, Turkey \\ ${ }^{4}$ Medipol University, Orthopedics and Traumatology, Istanbul, Turkey \\ Email: esatuygur@gmail.com,drbulentk@hotmail.com, “drmuratdemiroglu@gmail.com, \\ korhanozkan76@gmail.com,hakanturancift@yahoo.com
}

Received 11 October 2015; accepted 7 November 2015; published 10 November 2015

Copyright (C) 2015 by authors and Scientific Research Publishing Inc.

This work is licensed under the Creative Commons Attribution International License (CC BY).

http://creativecommons.org/licenses/by/4.0/

(c) (i) Open Access

\begin{abstract}
Osteoarthritis (OA) is the most prevalent form of arthritis and one of the leading causes of chronic disability which is becoming more pronounced as the population ages. Various genetic, biologic and mechanical factors contribute to disease process in OA. A large cascade of events leads to breakdown and degeneration of cartilage in a progressive manner ultimately resulting in the damage of the joint including the subchondral bone. Although majority of attention was given to chondral surface of the joint in the past, recently subchondral bone has been taken more and more attention during the investigation of degenerative phase in osteoarthritis. In our review we aimed to review the processes that were taken place during the osteoarthrosis especially in the subchondral bone and to give a new point of view for the further investigations.
\end{abstract}

\section{Keywords}

Osteoarthritis, Subchondral Bone

\section{Introduction}

Osteoarthritis (OA) is the most common chronic arthritis affecting patients over the age of 65 . The knee is the most common joint affected in OA. Various genetic, biologic and mechanical factors contribute to disease process in OA. OA is a slowly progressing joint degeneration which is characterized by cartilage damage, subchondral bone alterations, osteophyte formation and synovial tissue inflammation.

${ }^{*}$ Corresponding author. 


\section{Subchondral Bone and Its Features}

Specific anatomical regions have been described in the bone underlying joint cartilage, including the subchondral cortical plate, subchondral trabecular bone and sub-articular bone [1]-[3]. The most superficial layer of osteochondral tissues is articular cartilage which is very important in absorbing shock and maintaining normal joint environment [4].

Subchondral bone refers to the bony components which lie under calcified cartilage [1]-[3]. It is comprised of subchondral bone plate and subchondral trabecular bone. Subchondral bone plate consists of cortical bone, which is relatively nonporous and poorly vascularized. It is separated from the overlying articular cartilage by zone of calcified cartilage [4].

Deep regions in calcified cartilage which can not be nourished by synovial tissue are nourished by vascular supply between trabecular bone and calcified cartilage. Therefore cells in subchondral bone plate are nourished by those vessels [5].

Subchondral bone has two essential functions: stress absorption and maintenance of cartilage nutrient supply [5]. Relative to the subchondral bone plate subchondral trabecula is more porosive and metabolically active consisting blood vessels, sensory nerves and bone marrow [1].

Each region likely contributes differently to cartilage pathology. However, a lack of clear boundaries between these tissues by current imaging techniques generates some confusion in their study and thorough research will help to improve our understanding of subchondral bone properties [6].

\section{Alterations in Subchondral Bone in Osteoarthritis}

Main function of articular cartilage is load bearing. It has low water content, so this allows performing under compressive loads without failure. However articular cartilage cannot withstand high tension or shear stress for a long time and in the end cartilage splitting or fibrillation can occur. OA is characterized by an initial loss of proteoglycan from upper zone followed by the degradation of the collagen network.

Animal models for the most part show that changes in the subchondral bone are parallel to cartilage degradation [7].

Osteoarthritis appears to be a group of heterogeneous conditions that follow a common pathway of pathologic findings and clinical symptoms, including alterations in subchondral bone [8]. There are well described changes that are observed in both articular cartilage and subchondral bone in OA [4] [9]-[11]. Changes in the bone include sclerotic changes, thinning of articular cartilage [5], Thickening of the subchondral plate and subchondral cortical thickness, osteophyte formation, advancement of tidemark associated with vascular invasion of the calcified cartilage and the development of bone marrow lesions and bone cysts in the subchondral compartment [12] [13].

Although subchondral cortical plate is not very porous or vascular in nature subchondral compartment has a rich nerveous and vascular supply. The channels containing vessels and nerves are major source of pain in OA and when vascular supply reduces it leads negative effect on subchondral area [1] [3] [14] [15]. The distribution and intensity of these channels depends on age and compressive forces transmitting through cartilage and subchondral bone. Both the subchondral cortical plate and cancellous bone shows distinct difference in their behavior during progression of OA and hence must be regarded as separate units to understand the deformation of the joint.

The mechanical effects of loading on bone remodeling not only affect bone mass but also produce alterations in the contour and shape of the subchondral bone.

The subchondral bone explants from OA patients, secrete high levels of alkaline phosphatase, osteocalcin, osteopontin, Interleukin-6 (IL-6), Interleukin-8 (IL-8), and progressive ankylosis protein homolog (ANKH), urokinase plasminogen activator, prostaglandin and insulin growthfactor- 1 compared to normal bone explants.

There are many trials demonstrated that the presence of bone marrow lesions (BMLs) are closely related for structural deterioration in knee OA [16]-[21]. Roemer et al. attributed subchondral bone attrition to BMLs [22]. BMLs adjacent to the subchondral plate have been shown to have increased bone volume fraction and increased trabecular thickness, but reduced tissue mineral density [23], consistent with OA being associated with increased bone turnover. Both subchondral bone abnormalities are associated with cartilage loss as well [16] [24]. In an animal study, Hayami et al. demonstrated that as an antiresorptive treatment biphosphonate therapy may suppress bone resorption so later development of OA [25]. Crema et al. also indicated that subchondral cysts arise 
at the same site as BMLs [26].

There are some risk factors for the development of OA. The majority of them are obesity, previous trauma, overused, occupational habit, impact sports activity and genetics.

The American Academy of Orthopaedic Surgeons recommends that patients with knee or hip OA who are overweight, lose weight. Recent studies have also demonstrated the efficacy of an exercise program in improving muscle strength, mobility, and coordination and a decrease in the amount of paracetamol taken by patients with OA of the hip or knee.

The presence of other risk factors such as age, skeletal shape abnormalities, joint overload or obesity may have a synergistic effect for OA initiation [6]. These factors effect progression by directly or indirectly influencing subchondral bone. The microarchitecture of subchondral bone is closely associated with aging (Figure 1). In the literature it is shown that subchondral trabecular bone thickness and bone volume decrease, connectivity between trabecular bone and calcified cartilage becomes slower by age [1] [27] [28]. The negative effect of obesity on bone health may be attributed to increased fat acid, adipokines and inflammatory cytokines such as interleukin-beta. However in another study it is indicated that increased biomechanical loads in obese patients lead to subchondral bone stiffness [29]. Although moderate biomechanical loading protects from OA, excessive loading cause development of OA. It is shown that subchondral bone responds to the stress of exercise by increasing bone formation and density [30]. Therefore Colon et al. indicated that subchondral fragmentation and microfracturesmay cause subchondral necrosis and sclerosis in racehorses [31]. Due to causing joint malalignment and microfractures traumatic ligament injuries may also affect subchondral bone [14].

Brooke and Helal [32] reported that venous drainage of subchondral bone is defective. Arnoldi et al. demonstrated that intact arterial flow with venous drainage deficiency leading to subchondral intraosseous venous hypertension was indicated [33]. They concluded that subchondral bone hypertension may cause non-traumatic ischemic necrosis. Kiaer et al. [34] also showed that increased intraosseous pressure consequently leads to hypoxia in the femoral head of hips with early osteoarthritis and in ischemic necrosis of bone. They concluded that necrosis of bone trabeculae and bone marrow are early manifestations of both osteoarthritis and ischemic necrosis of bone [34]. Therefore, as Imhof et al. reported hypertension in subchondral bone decreases nourishment at that region [35]. In a microangiographic study, Bakker et al. reported that thrombus blocked vessels may also predispose OA formation [36]. However hypertension and hypercoagulopathy are generally seen together [37] [38]. So in OA the questions of which one is responsible for or are they consequences of OA are controversial.

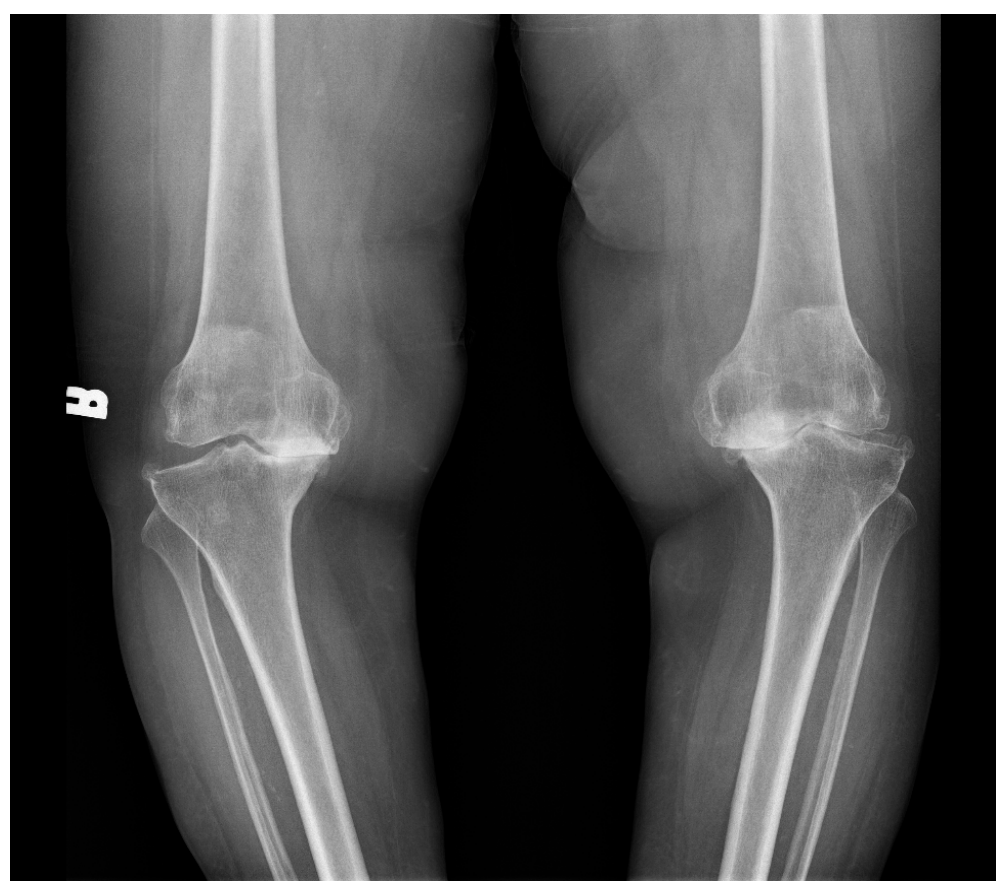

Figure 1. Subchondral sclerosis in patient with medial and lateral compartment arthrosis. 


\section{Conclusion}

In adopting the "joint as an organ" approach to understanding, diagnosing and treating OA, subchondral bone pathology should be further examined to characterize its involvement and importance.

\section{Author Contributions}

EU: conception and design, acquisition of data and analysis; BK: acquisition of data and analysis; MD: acquisition of data and analysis; KO: conception and design and interpretation of data; HTC: acquisition of data and analysis.

\section{Conflict of Interest}

The authors have no conflicts of interest or financial ties to disclose.

\section{References}

[1] Li, G., Yin, J., Gao, J., Cheng, T.S., Pavlos, N.J., Zhang, C., et al. (2013) Subchondral Bone in Osteoarthritis: Insight into Risk Factors and Microstructural Changes. Arthritis Research \& Therapy, 15, 223. http://dx.doi.org/10.1186/ar4405

[2] Burr, D.B. and Gallant, M.A. (2012) Bone Remodelling in Osteoarthritis. Nature Reviews Rheumatology, 8, 665-673. http://dx.doi.org/10.1038/nrrheum.2012.130

[3] Madry, H., van Dijk, C.N. and Mueller-Gerbl, M. (2010) The Basic Science of the Subchondral Bone. Knee Surgery, Sports Traumatology, Arthroscopy, 18, 419-433. http://dx.doi.org/10.1007/s00167-010-1054-z

[4] Goldring, M.B. and Goldring, S.R. (2010) Articular Cartilage and Subchondral Bone in the Pathogenesis of Osteoarthritis. Annals of the New York Academy of Sciences, 1192, 230-237. http://dx.doi.org/10.1111/j.1749-6632.2009.05240.x

[5] Kawcak, C.E., McIlwraith, C.W., Norrdin, R.W., Park, R.D. and James, S.P. (2001) The Role of Subchondral Bone in Joint Disease: A Review. Equine Veterinary Journal, 33, 120-126. http://dx.doi.org/10.1111/j.2042-3306.2001.tb00589.x

[6] Roman-Blas, J.A. and Herrero-Beaumont, G. (2014) Targeting Subchondral Bone in Osteoporotic Osteoarthritis. Arthritis Research \& Therapy, 16, 494. http://dx.doi.org/10.1186/s13075-014-0494-0

[7] Moodie, J.P., Stok, K.S., Müller, R., Vincent, T.L. and Shefelbine, S.J. (2011) Multimodal Imaging Demonstrates Concomitant Changes in Bone and Cartilage after Destabilisation of the Medial Meniscus and Increased Joint Laxity. Osteoarthritis Cartilage, 19, 163-170. http://dx.doi.org/10.1016/j.joca.2010.11.006

[8] Kuroki, K., Cook, C.R. and Cook, J.L. (2011) Subchondral Bone Changes in Three Different Canine Models of Osteoarthritis. Osteoarthritis Cartilage, 19, 1142-1149. http://dx.doi.org/10.1016/j.joca.2011.06.007

[9] Martel-Pelletier, J. and Pelletier, J.P. (2010) Is Osteoarthritis a Disease Involving Only Cartilage or Other Articular Tissues? Eklem Hastalik Cerrahisi, 21, 2-14.

[10] Kwan Tat, S., Lajeunesse, D., Pelletier, J.P. and Martel-Pelletier, J. (2010) Targeting Subchondral Bone for Treating Osteoarthritis: What Is the Evidence? Best Practice \& Research Clinical Rheumatology, 24, 51-70. http://dx.doi.org/10.1016/j.berh.2009.08.004

[11] Edmonds, S. (2009) Therapeutic Targets for Osteoarthritis. Maturitas, 63, 191-194. http://dx.doi.org/10.1016/j.maturitas.2009.03.015

[12] Tanamas, S.K., Wluka, A.E., Pelletier, J.P., Martel-Pelletier, J., Abram, F., Wang, Y., et al. (2010) The Association between Subchondral Bone Cysts and Tibial Cartilage Volume and Risk of Joint Replacement in People with Knee Osteoarthritis: A Longitudinal Study. Arthritis Research \& Therapy, 12, R58. http://dx.doi.org/10.1186/ar2971

[13] Goldring, S.R. (2009) Role of Bone in Osteoarthritis Pathogenesis. Medical Clinics of North America, 93, 25-35. http://dx.doi.org/10.1016/j.mcna.2008.09.006

[14] Findlay, D.M. (2012) Subchondral Bone in Osteoarthritis. INTECH Open Access Publisher, Rijeka.

[15] Holmdahl, D.E. and Ingelmark, B.E. (1950) The Contact between the Articular Cartilage and the Medullary Cavities of the Bone. Acta Orthopaedica Scandinavica, 20, 156-165. http://dx.doi.org/10.3109/17453675009043414

[16] Hunter, D.J., Zhang, Y., Niu, J., Goggins, J., Amin, S., LaValley, M.P., et al. (2006) Increase in Bone Marrow Lesions Associated with Cartilage Loss: A Longitudinal Magnetic Resonance Imaging Study of Knee Osteoarthritis. Arthritis \& Rheumatism, 54, 1529-1535. http://dx.doi.org/10.1002/art.21789 
[17] Dore, D., Martens, A., Quinn, S., Ding, C., Winzenberg, T., Zhai, G., et al. (2010) Bone Marrow Lesions Predict Site-Specific Cartilage Defect Development and Volume Loss: A Prospective Study in Older Adults. Arthritis Research \& Therapy, 12, R222. http://dx.doi.org/10.1186/ar3209

[18] Felson, D.T., McLaughlin, S., Goggins, J., LaValley, M.P., Gale, M.E., Totterman, S., et al. (2003) Bone Marrow Edema and Its Relation to Progression of Knee Osteoarthritis. Annals of Internal Medicine, 139, 330-336. http://dx.doi.org/10.7326/0003-4819-139-5_Part_1-200309020-00008

[19] Zhai, G., Blizzard, L., Srikanth, V., Ding, C., Cooley, H., Cicuttini, F., et al. (2006) Correlates of Knee Pain in Older Adults: Tasmanian Older Adult Cohort Study. Arthritis \& Rheumatism, 55, 264-271. http://dx.doi.org/10.1002/art.21835

[20] Garnero, P., Peterfy, C., Zaim, S. and Schoenharting, M. (2005) Bone Marrow Abnormalities on Magnetic Resonance Imaging Are Associated with Type II Collagen Degradation in Knee Osteoarthritis: A Three-Month Longitudinal Study. Arthritis \& Rheumatism, 52, 2822-2829. http://dx.doi.org/10.1002/art.21366

[21] Carrino, J.A., Blum, J., Parellada, J.A., Schweitzer, M.E. and Morrison, W.B. (2006) MRI of Bone Marrow EdemaLike Signal in the Pathogenesis of Subchondral Cysts. Osteoarthritis Cartilage, 14, 1081-1085. http://dx.doi.org/10.1016/j.joca.2006.05.011

[22] Roemer, F.W., Neogi, T., Nevitt, M.C., Felson, D.T., Zhu, Y., Zhang, Y., et al. (2010) Subchondral Bone Marrow Lesions Are Highly Associated with, and Predict Subchondral Bone Attrition Longitudinally: The MOST Study. Osteoarthritis Cartilage, 18, 47-53. http://dx.doi.org/10.1016/j.joca.2009.08.018

[23] Hunter, D.J., Gerstenfeld, L., Bishop, G., Davis, A.D., Mason, Z.D., Einhorn, T.A., et al. (2009) Bone Marrow Lesions from Osteoarthritis Knees a Recharacterized by Sclerotic Bone That Is Less Well Mineralized. Arthritis Research \& Therapy, 11, R11. http://dx.doi.org/10.1186/ar2601

[24] Neogi, T., Nevitt, M., Niu, J., Sharma, L., Roemer, F., Guermazi, A., et al. (2010) Subchondral Bone Attrition May Be a Reflection of Compartment-Specific Mechanical Load: The MOST Study. Annals of the Rheumatic Diseases, 69, 841-844. http://dx.doi.org/10.1136/ard.2009.110114

[25] Hayami, T., Pickarski, M., Wesolowski, G.A., McLane, J., Bone, A., Destefano, J., et al. (2004) The Role of Subchondral Bone Remodeling in Osteoarthritis: Reduction of Cartilage Degeneration and Prevention of Osteophyte Formation by Alendronate in the Rat Anterior Cruciate Ligament Transection Model. Arthritis \& Rheumatism, 50, 1193-1206. http://dx.doi.org/10.1002/art.20124

[26] Crema, M.D., Roemer, F.W., Zhu, Y., Marra, M.D., Niu, J., Zhang, Y., et al. (2010) Subchondral Cyst Like Lesions Develop Longitudinally in Areas of Bone Marrow Edema-Like Lesions in Patients with or at Risk for Knee Osteoarthritis: Detection with MR Imaging-The MOST Study. Radiology, 256, 855-862. http://dx.doi.org/10.1148/radiol.10091467

[27] Carbone, L.D., Nevitt, M.C., Wildy, K., Barrow, K.D., Harris, F., Felson, D., et al. (2004) The Relationship of Antiresorptive Drug Use to Structural Findings and Symptoms of Knee Osteoarthritis. Health, Aging and Body Composition Study. Arthritis \& Rheumatism, 50, 3516-3525. http://dx.doi.org/10.1002/art.20627

[28] Dequeker, J., Goris, P. and Uytterhoeven, R. (1983) Osteoporosis and Osteoarthritis (Osteoarthrosis). Anthropometric Distinctions. JAMA, 249, 1448-1451. http://dx.doi.org/10.1001/jama.1983.03330350024020

[29] Scotece, M. and Mobasheri, A. (2015) Leptin in Osteoarthritis: Focus on Articular Cartilage and Chondrocytes. Life Sciences, 140, 75-78. http://dx.doi.org/10.1016/j.lfs.2015.05.025

[30] Young, D.R., Richardson, D.W., Markel, M.D. and Nunamaker, D.M. (1991) Mechanical and Morphometric Analysis of the Third Carpal Bone of Thorough Breds. American Journal of Veterinary Research, 52, 402-409.

[31] Colon, J.L., Bramlage, L.R., Hance, S.R. and Embertson, R.M. (2000) Qualitative and Quantitative Documentation of the Racing Performance of 461 Thorough Bred Race Horses after Arthroscopic Removal of Dorsoproximal First Phalanx Osteochondral Fractures (1986-1995). Equine Veterinary Journal, 32, 475-481. http://dx.doi.org/10.2746/042516400777584640

[32] Brookes, M. and Helal, B. (1968) Primary Osteoarthritis, Venous Engorgement and Osteogenesis. The Journal of Bone \& Joint Surgery (British Volume), 50, 493-504.

[33] Arnoldi, C.C. (1994) Vascular Aspects of Degenerative Joint Disorders. A Synthesis. Acta Orthopaedica Scandinavica, 65, 3-82. http://dx.doi.org/10.3109/17453679409155226

[34] Kiaer, T., Pedersen, N.W., Kristensen, K.D. and Starklint, H. (1990) Intra-Osseous Pressure and Oxygentension in Avascular Necrosis and Osteoarthritis of the Hip. The Journal of Bone \& Joint Surgery (British Volume), 72, 10231030.

[35] Bakker, A., Klein-Nulend, J. and Burger, E. (2004) Shear Stress Inhibits While Disuse Promotes Osteocyte Apoptosis. Biochemical and Biophysical Research Communications, 320, 1163-1168. http://dx.doi.org/10.1016/j.bbrc.2004.06.056 
[36] Imhof, H., Breitenseher, M., Kainberger, F. and Trattnig, S. (1997) Degenerative Joint Disease: Cartilageor or Vascular Disease? Skeletal Radiology, 26, 398-403. http://dx.doi.org/10.1007/s002560050254

[37] Korompilias, A.V., Ortel, T.L. and Urbaniak, J.R. (2004) Coagulation Abnormalities in Patients with Hip Osteonecrosis. Orthopedic Clinics of North America, 35, 265-271. http://dx.doi.org/10.1016/j.ocl.2004.02.004

[38] Zhang, G., Qin, L., Sheng, H., Yeung, K.W., Yeung, H.Y., Cheung, W.H., et al. (2007) Epimedium-Derived Phytoestrogen Exert Beneficial Effect on Preventing Steroid-Associated Osteonecrosis in Rabbits with Inhibition of both Thrombosis and Lipid-Deposition. Bone, 40, 685-692. http://dx.doi.org/10.1016/j.bone.2006.10.026

\section{Abbreviations and Acronyms}

OA: osteoarthritis

BMLs: bone marrow lesions

IL: interleukin

ANKH: ankylosis protein homolog 